\title{
Synthesis and Characterizations of ZnO Thin Films Grown by Physical Vapor Deposition Technique
}

\author{
Raghad Y. Mohammed ${ }^{1 *}$, Sabah M. Ahmed ${ }^{1}$, Ahmed Fattah Abdulrahman², Samir Mustafa Hamad ${ }^{4}$ \\ ${ }^{1}$ Department of Physics, College of Science, University of Duhok, Kurdistan Region, Iraq, (ssraghad, abma62)@uod.ac \\ ${ }^{2}$ Department of Physics, Faculty of Science, University of Zakho, Kurdistan Region, Iraq, ahmed.abdulrahman@uoz.edu.krd \\ ${ }^{3}$ Scientific Research Center, Soran University, Soran 44008, Erbil, Iraq, samir.hamad@soran.edu.iq \\ * Correspondence: ssraghad@uod.ac
}

\begin{abstract}
In the current study, Zinc oxide (ZnO) thin films have been synthesized over the whole the glass-slide substrate by utilizing the physical vapor deposition (PVD) technique. The Zinc (Zn) seed layer was deposited by heating the high purity $\mathrm{Zn}$ powder by using a molybdenum (Mo) boat at $37.503 \times 10^{-3}$ Torr vacuum pressure of the PVD chamber. The $\mathrm{ZnO}$ thin films were fabricated by oxidation of the $\mathrm{Zn}$ seed layer coated glass-slide substrate at $400{ }^{\circ} \mathrm{C}$. The morphological, chemical compositions, crystal quality, structural and optical properties of fabricated $\mathrm{ZnO}$ thin film were characterized and studied utilizing several characterization techniques. The results found that the high distribution density, homogenous, uniform, and high-quality ZnO thin film was grown over the entire substrate. The synthesized ZnO thin film with a thickness of $130 \mathrm{~nm}$ was grown with high purity and polycrystalline hexagonal-Wurtzite phase of ZnO. The sharp, and dominant diffraction peak was observed at peak position 34.3375 along (002) plane and c-axis. The investigated crystal size, dislocation density, and interplanar spacing were about $13.33 \mathrm{~nm}, 5.63 \times 10^{-5} \mathrm{~A}^{\circ}$, and $2.609 \mathrm{~A}^{\circ}$, respectively. Also, $\mathrm{UV}$-visible spectroscopy results show the high transmittance and low absorbance in the visible (Vis.) region and were about $90 \%$, and the transmittance decreases sharply near the UV region at a wavelength around $383 \mathrm{~nm}$. Besides, obtained the energy band-gap $\left(E_{\mathrm{g}}\right)$ was about $3.24 \mathrm{eV}$.
\end{abstract}

Keywords: Zinc Oxide, Thin Films, PVD, Molybdenum boat, Glass Substrate

Received: November $2^{\text {nd }}$, 2020 / Accepted: December $24^{\text {th }}, 2020$ / Online: December $31^{\text {st }}, 2020$

\section{INTRODUCTION}

The fabrication, examination, and characterization of Zinc Oxide $(\mathrm{ZnO})$ thin film have been an active and functional field of different research for decades [1]. Recently, many scientists and researchers have been extensively studied and worked on the wide energy gap semiconductor materials includes $\mathrm{ZnO}$ due to their excellent properties and uses in optoelectronic (OPE) devices [2]. The $\mathrm{ZnO}$ has a hexagonal wurtzite structure and direct optical energy gap which is $3.37 \mathrm{eV}$ at room temperature (RT) [3-6 ]. At RT, the $\mathrm{ZnO}$ has the wider and larger exciton binding energy which is $60 \mathrm{meV}$ compared to the Gallium Nitrate $(\mathrm{GaN})$ which is $(20 \mathrm{meV})[4,7]$. Also, $\mathrm{ZnO}$ has a high chemical, thermal, and electrical stability [8]. The crystal growth of $\mathrm{ZnO}$ can be grown by using simple fabrication technology which is the other benefit of $\mathrm{ZnO}$ [9]. Therefore, it can say that zinc oxide is highly interesting for several areas of very high technological implementations and manufacturing [2].
The zinc oxide thin films have been emerged very interesting due to their excellent implementations, as the window layer (WL) in solar cell system, and as the transparent conductingoxide (TCO) [10, 11]. Due to the very high optical transmittance (T) in the visible (Vis.) region and an excellent piezoelectric (PE) characteristic, several another uses of $\mathrm{ZnO}$ thin films includes the surface acoustic wave device, and the film bulk acoustic resonator filter (FBARF)have also studied and investigated [12, 13]. The zinc oxide thin films have been prepared and synthesized by using different physical and chemical methods and techniques [14]. These methods include the chemical bath deposition method (CBD), pulsed laser 
deposition (PLD), molecular beam epitaxy (MBE), radio frequency (RF) magnetron sputtering technique, physical vapor deposition (PVD) technique, metal-organic chemical vapor deposition (MO-CVD), spray pyrolysis (SP), sol-gel method, hydrothermal method, an ultrasonic spray method [15-18]. Notwithstanding, the PVD technique is a very simple, low-cost, reproducible, and easy technique that can be utilized and scaled up for the synthesis of a large range and types of different $\mathrm{ZnO}$ nanostructures such as nanorings, nanohelixes, nanowires, nanoparticles, nanobelts, thin films, nanorods, and nanoneedles [19].

In this work, an easy and simple physical vapor deposition (PVD) technique with $37.503 \times 10^{-3}$ Torr vacuum pressure of the PVD chamber. was used to deposit the $\mathrm{ZnO}$ thin films on the glass substrates. The morphological, chemical compositions, crystal quality, structural and optical properties of fabricated $\mathrm{ZnO}$ thin film were characterized and studied utilizing several characterization techniques.

\section{EXPERIMENTAL DETAILS}

In this work, all utilized beginning materials such as Zinc ( $\mathrm{Zn})$ powder, and Ethanol $\left(\mathrm{C}_{2} \mathrm{H}_{6} \mathrm{O}\right)$ purchase from the Company of Sigma-Aldrich without further purification. The distilledwater (DW) has been utilized for remedies and synthesis processes. The microscopic glass slide was employed as the substrates for zinc oxide thin film deposition. Before the deposition process of $\mathrm{ZnO}$ thin film, the glass substrates were prepared with a dimension of $(25 \times 75 \times 1) \mathrm{mm}^{3}$. The glass-slide substrates were cleaned by soaking the glass substrates in the solution of in Chromic Acid $\left(\mathrm{H}_{2} \mathrm{CrO}_{4}\right)$ for 1 day, and then taken off from the acid solution and rinsed with distilled water, and Ethanol $\left(\mathrm{C}_{2} \mathrm{H}_{5} \mathrm{OH}\right)$ for $15 \mathrm{~min}$, respectively. Besides, the glass substrates have been cleaned ultrasonically with distilled water for $15 \mathrm{~min}$, and dried in air at room temperature, and kept in a desiccator [20]. The mentioned cleaning process provides good adhesion, growth nucleation center, and uniform synthesis of thin films [21]. The $130 \mathrm{~nm}$ thickness of $\mathrm{ZnO}$ thin film was synthesized by using a one-step PVD technique. The PVD deposition process was carried out by evaporating the $137.32 \mathrm{mg}$ of high purity (99.6\%) Zinc (Zn) powder on the whole cleaned glass-slide substrates by utilizing the molybdenum (Mo) boat to heat the $\mathrm{Zn}$ powder. The vacuum pressure was $37.503 \times 10^{-3} \mathrm{Torr}$ of the PVD chamber. Also, the glass-slide substrates have been rotated during PVD evaporating process by using a uniform rotating substrates holder that holds the 12 glass substrates samples. After finishing the PVD synthesis process of $\mathrm{Zn}$ thin film, the deposited the $\mathrm{Zn}$ upon the substrates were bring out of the PVD chamber and transferred into the laboratory annealing furnace at $400^{\circ} \mathrm{C}$ for $1.5 \mathrm{~h}$ to get the $\mathrm{ZnO}$ thin films. A schematic diagram for the synthesis of $\mathrm{ZnO}$ thin film is shown in Figure (1).

The surface morphological properties, chemical composition, crystal quality, and structural properties of synthesized $\mathrm{ZnO}$ thin film have been characterized and studied by utilizing the field-emission scanning electron microscopy (FE-SEM) (SEM 4500-Quanta), energy-dispersive X-ray (EDX) analysis, and analytical (XRD) X- Pert PRO $(\mathrm{Cu} \mathrm{K \alpha}=$ $1.5406 \mathrm{~A}^{\circ}$ at $\left.40 \mathrm{kV}, 30 \mathrm{~mA}\right)$ in the $2 \theta$ range of $\left(20^{\circ}\right.$ to $\left.70^{\circ}\right)$ with the rate of scanning was $1 \%$ min, respectively.

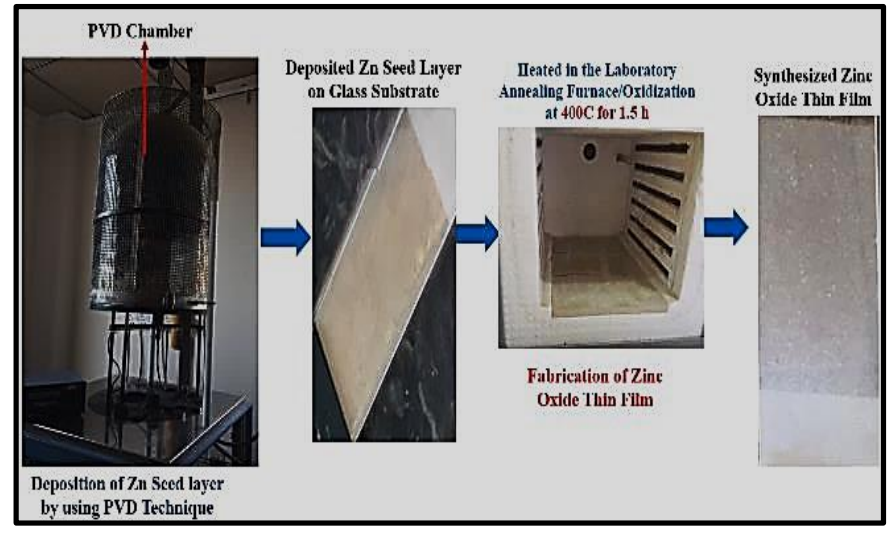

Fig. 1. Schematic Diagram of Synthesized ZnO Thin Film

The optical properties, optical transmittance spectrum, and energy band gap of the $\mathrm{ZnO}$ thin film was studied by utilizing the ultraviolet (UV-Vis.) spectrophotometer in the range of (300-1000) $\mathrm{nm}$. The interplanar distance (d) of the synthesized $\mathrm{ZnO}$ thin film along diffraction peak (002) has been calculated by using Bragg's law [22]:

$$
\frac{1}{d^{2}}=\frac{4}{3}\left(\frac{h^{2}+h k+k^{2}}{a^{2}}\right)+\frac{l^{2}}{c^{2}}
$$

Where $a, c$ and hkl are the lattice parameters constants, and miller indices, respectively.

The average crystal size (D) and the number of defects which is called the dislocation density $(\delta)$ of the deposited $\mathrm{ZnO}$ thin film along (002) diffraction peak was obtained using Scherrer's equation [23]:

$$
\begin{aligned}
& D=\frac{k \lambda}{\beta \cos \theta} \\
& \delta=\frac{1}{D^{2}}
\end{aligned}
$$

Where $\mathrm{D}, \delta, \theta, \mathrm{k}, \beta$, and $\lambda$ are the average crystal size, dislocation density, diffraction Bragg's angle, constant which is equal to 0.9, full width at half maximum (FWHM), and wavelength of the X-ray source which is equal to 1.54050 Angstrom, accordingly.

The energy band gap energy (Eg) of synthesis $\mathrm{ZnO}$ thin film

$$
(\alpha h v)^{2}=A\left(h v-E_{g}\right)^{n}
$$

was calculated from the Tauc's relation [24, 25].

Where $\alpha, \mathrm{h} v, \mathrm{~A}, \mathrm{Eg}$, and $\mathrm{n}$ are the absorption coefficient, the photon energy, constant, the optical band gap energy and depends on the transmission type $(\mathrm{n}=2$ for indirect transmission and $\mathrm{n}=(1 / 2)$ due to direct transmission of $\mathrm{ZnO})$. The $\alpha$ coefficient was determined by [26].

$$
\alpha=\frac{\ln \left(\frac{1}{\mathrm{~T}}\right)}{\mathrm{d}}
$$

Where ( $\mathrm{T}$ and $\mathrm{d}$ ) are the transmittance and thickness of synthesized $\mathrm{ZnO}$ thin film sample. 


\section{RESULTS AND DISCUSSION}

The $\mathrm{ZnO}$ surface topography top-view of the synthesized $\mathrm{ZnO}$ thin film with different magnifications using FESEM analysis are shown in Figure 2. It can be seen that the homogenous, uniform, high distribution density, and highquality thin film of $\mathrm{ZnO}$ was deposited over the whole substrate. For a deep investigation of $\mathrm{ZnO}$ thin film morphology, the synthesized $\mathrm{ZnO}$ sample was characterized by using energy dispersive X-ray (EDX) analysis as shown in Figure 3 (a). The EDX spectrum of the deposited $\mathrm{ZnO}$ thin film sample was taken for the FESEM characterizations which indicated that the $\mathrm{ZnO}$ thin film sample produced through the PDV technique had a clean phase of $\mathrm{ZnO}$. From Figure 3 (a), the EDX analysis of the $\mathrm{ZnO}$ thin film indicated that the fabricated $\mathrm{ZnO}$ thin film sample contained zinc $(\mathrm{Zn})$, and oxygen $(\mathrm{O})$. The EDX spectrum showed one robust peak for $\mathrm{Zn}$ around $1 \mathrm{keV}$ correspondingly and a singular peak for oxygen at $\sim 0.5 \mathrm{keV}$, which is typical for $\mathrm{ZnO}$ thin films [27]. The high intensity of $\mathrm{Zn}$ and $\mathrm{O}$ peaks displayed that the synthesized thin film sample was mostly $\mathrm{ZnO}$. Figure 3 exposed that the produced $\mathrm{ZnO}$ thin film sample possessed $80.74 \% \mathrm{Zn}$ weight (Wt) percent associated with only $19.26 \% \mathrm{O}$ weight percent reveal nearly 3.7:1 ratio for $\mathrm{Zn}$ and $\mathrm{O}$, respectively. These obtained values of $\mathrm{Zn}$ and $\mathrm{O}$ are in good coincides with the theoretically expected stoichiometric $\mathrm{Wt} \%$ of $\mathrm{Zn}$ and $\mathrm{O}$, i.e., $80.3 \%$ and $19.7 \%$ respectively [28]. Accordingly, the EDX analysis emphasizes that the $\mathrm{ZnO}$ thin film deposited by the PVD technique possessed high purity elemental composition. Besides, the atomic $\%$ of $\mathrm{Zn}$ was $50.64 \%$ accompanied by $49.34 \%$ for $\mathrm{O}$ atomic percent giving roughly a $1: 1$ ratio for $\mathrm{Zn}$ and $\mathrm{O}$, in this order. Further details regarding to the distributions and the elemental mapping of $\mathrm{Zn}$ and $\mathrm{O}$ elements are shown in Fig.4 (b).

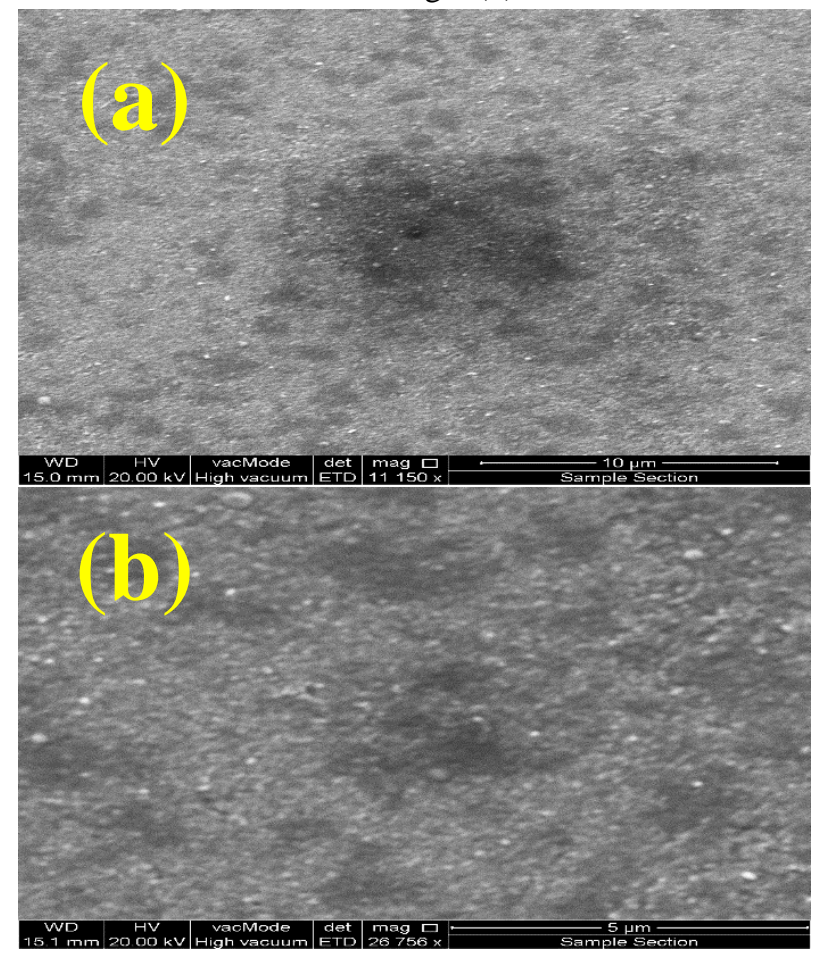

Fig. 2. Surface Morphology (Top-View) FESEM Image of Synthesized ZnO Thin Film (a) low Magnification and (b) High Magnification

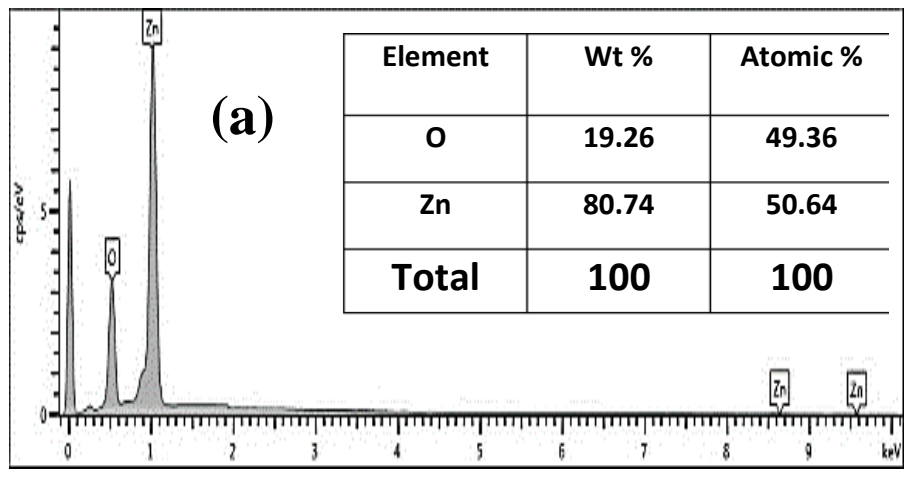

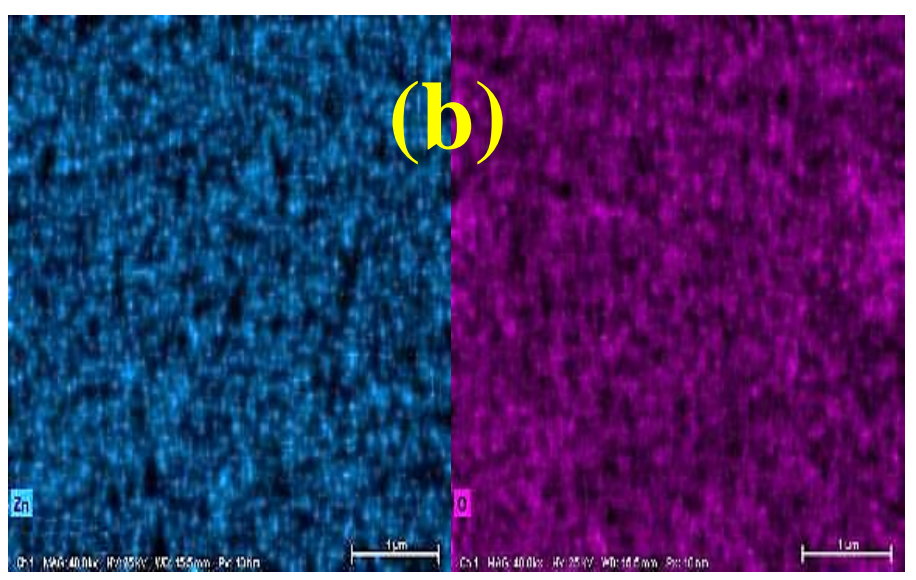

Fig. 3. (a) The EDX Spectrum Analysis of the synthesized ZnO Thin Film. (b) Elemental Mapping analysis for 3.7 Zinc:1Oxygen wt.\% ratio for ZnO Thin Film Synthesized by using PVD Technique.

The X-ray diffraction (XRD) pattern of $\mathrm{ZnO}$ thin film deposited using the PVD technique is demonstrated in Figure 4. From the XRD pattern, it can investigate that all the diffraction peaks in all XRD patterns show the polycrystalline wurtzitehexagonal phase of $\mathrm{ZnO}$ corresponded to the standard spectrum (JCPDS cards No. 98-016-3383). Besides, no diffraction peaks from other defects (impurities) were observed, proving that the high purity of the $\mathrm{ZnO}$ nanocrystal phase is performed. From Figure 4, it can be noted that the fabricated $\mathrm{ZnO}$ thin film sample shows the sharp, strong, and dominant peak at peak position 2 $q=34.3375$ corresponding to the diffraction peak (002) along the $\mathrm{c}$-axis of $\mathrm{ZnO}$. The $\mathrm{ZnO}$ thin film sample resorted to growing in the orientation alongside the (002) plane to the free-surface energy (E) density of this orientation was lowest in the crystal of the $\mathrm{ZnO}$ [29]. The sharp, dominant, and strong peak alongside (002) diffraction peak also proven that the $\mathrm{ZnO}$ thin film was preferentially formed alongside the c-axis of the hexagonal-wurtzite $\mathrm{ZnO}$ structure with very weak diffractions peaks from other surfaces, which is confirmed that the $\mathrm{ZnO}$ thin film was were vertically well-aligned grow on the whole surface of glass-slide substrates. The investigated interplanar distance of synthesized $\mathrm{ZnO}$ thin film along (002) diffraction peak was about $2.609 \AA$. Also, the investigated crystal size and dislocation density of fabricated $\mathrm{ZnO}$ thin film alongside diffraction peak (002) was about $13.33 \mathrm{~nm}$, and $5.63 \times 10-5 \AA$, respectively. 


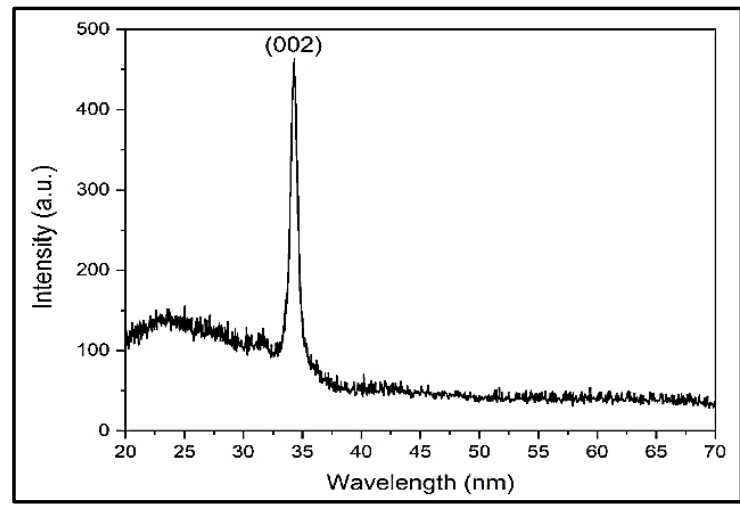

Fig. 4. XRD Pattern of Synthesized ZnO Thin Film

The optical properties of deposited $\mathrm{ZnO}$ thin film have studied the investigation of the optical transmissions and absorptions spectra using UV-Vis spectrometer. Figure 5 shows the transmittance of $\mathrm{ZnO}$ thin film with a wavelength range of $(300-1000) \mathrm{nm}$. In the visible region, the fabricated $\mathrm{ZnO}$ thin film samples have high transmittance of more than $90 \%$ and low transmittance in the UV region. There is a sharp decrease in transmittance near the UV region at a wavelength around 383 $\mathrm{nm}$. A redshift can be observed due to the change of the $\mathrm{ZnO}$ thin film's optical properties [30]. The shift was due to the decrement of the energy bandgap [8] and maybe assigned to the internal stress and the light scattering effects in the films caused by the random distribution of the thin film [14]. The optical absorption spectrum of the produced $\mathrm{ZnO}$ thin film with a wavelength range between $300 \mathrm{~nm}$ to $100 \mathrm{~nm}$ as shown in the inset of Figure 5a. The absorbance spectrum shows strong absorption i.e. high absorbance in the UV region at wavelength below $400 \mathrm{~nm}$ and high transparency low absorbance in the visible region, which are the characteristics of $\mathrm{ZnO}$ [23]. The decrease in absorbance at long wavelengths is regarded to the impurities of the $\mathrm{ZnO}$ thin film such as interstitial $\mathrm{Zn}$ atoms and oxygen vacancies, which act as donor defects [26]. Also, the investigated optical $\mathrm{E}_{\mathrm{g}}$ of deposited $\mathrm{ZnO}$ thin film was about $3.24 \mathrm{eV}$, as shown in Figure 6. The obtained $\mathrm{E}_{\mathrm{g}}$ value is in good agreement with previous studies [29].

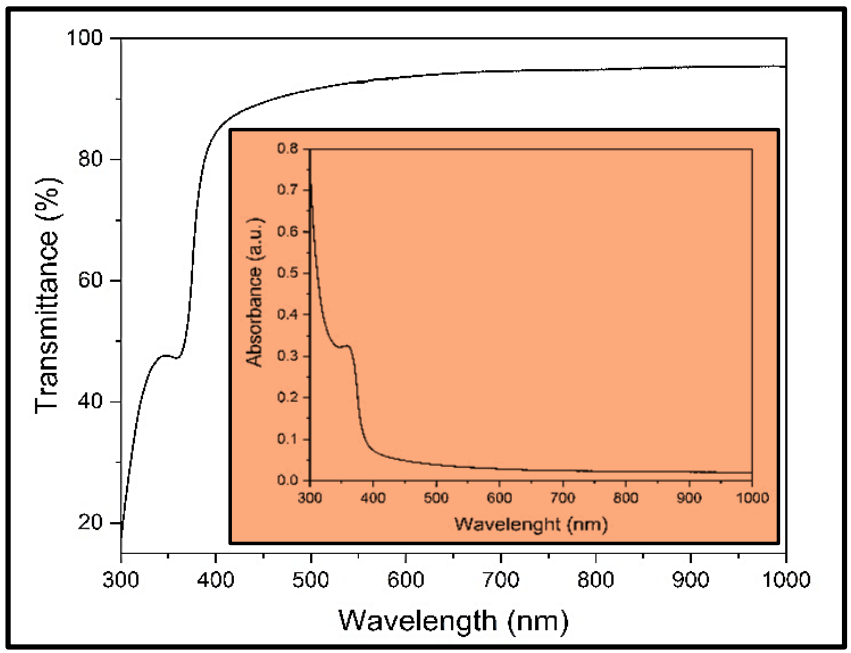

Fig. 5. Optical Transmission Spectrum of the Synthesized ZnO Thin film, the inset is Optical Absorption Spectrum of ZnO Thin Film.

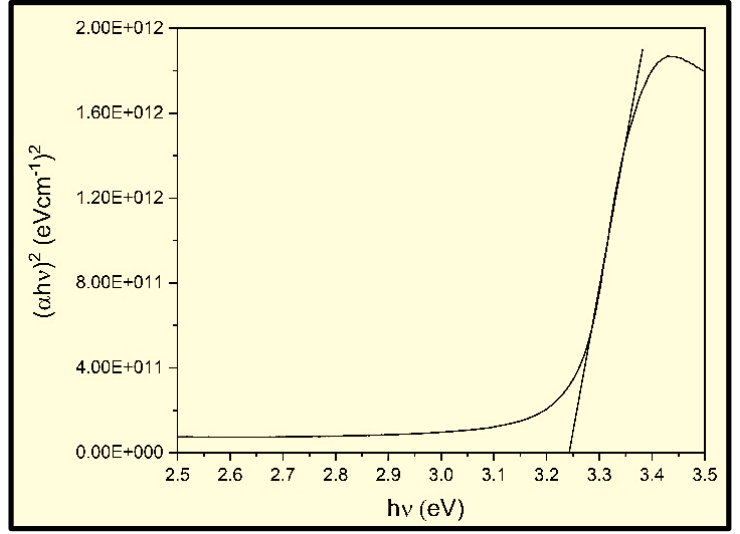

Fig. 6. Tauc plot (alpha hv) ${ }^{2}$ Versus Energy Band Gap (hv) of the ZnO Thin Film

\section{CONCLUSION}

A high-quality and uniform $\mathrm{ZnO}$ thin film had been fabricated successfully upon the entire glass substrate via PVD technique at $37.503 \times 10^{-3}$ Torr. The high purity zinc powder was heat in a chamber of PVD via molybdenum boat and oxidation at $400{ }^{\circ} \mathrm{C}$ to get $\mathrm{ZnO}$ thin film. The fabricated $\mathrm{ZnO}$ thin film was grown with a polycrystalline wurtzite-hexagonal phase of $\mathrm{ZnO}$. Also, the synthesized $\mathrm{ZnO}$ thin film shows low absorbance and high transmittance in the visible region, and the average transmittance dropped sharply close to the UV region at $383 \mathrm{~nm}$. Besides, obtained the energy band-gap $\left(\mathrm{E}_{\mathrm{g}}\right)$ was about $3.24 \mathrm{eV}$.

\section{ACKNOWLEDGMENT}

The Authors are thankful to University of Duhok for fully supported by them .Special thanks to University of Zakho, and the authors also would like to thanks Soran research center at Soran University for providing all the facilities to perform the research work.

\section{REFERENCES}

[1] G. Xiangdong, L. Xiaomin, and Y. Weidong, "Preparation and characterization of highly oriented $\mathrm{ZnO}$ film by ultrasonic assisted SILAR method", Journal Wuhan University of Technology, Materials Science Edition, vol. 20, No. 3, pp. 23-26, 2005.

[2] D Aryanto, W N Jannah, Masturi, T Sudiro, A. S Wismogroho, Sugianto, P Marwoto, and P Sebayang, "Preparation and structural characterization of $\mathrm{ZnO}$ thin films by sol-gel method", IOP Conf. Series: Journal of Physics: Conf. Series 817, pp. 012025, 2017.

[3] Ahmed F. Abdulrahman, Sabah M. Ahmed and Naser M. Ahmed, "The Influence of the Growth Time on the Size and Alignment of $\mathrm{ZnO}$ Nanorods", Science Journal of UOZ, Vol. 5, No.1, p. 128-135, 2017.

[4] S. A. Kamaruddin, K-Y. Chan, H-K. Yow, M. Z. Sahdan, H. Saim and D. Knipp," Luminescence characteristics of energy transfer between $\mathrm{Ce} 3+$ and $\mathrm{Eu} 2+$ in NaMgPO4 phosphor", Appl. Phys. A Vol.104, pp. $263,2011$.

[5] A. Gahtar, A. Rahal, B. Benhaoua and S. Benramache, "A comparative study on structural and optical properties of $\mathrm{ZnO}$ and $\mathrm{Al}$-doped $\mathrm{ZnO}$ thin films obtained by ultrasonic spray method using different solvents", Optik, Vol. 125 pp. 3674, 2014.

[6] I. Jena, S. N. Das, D. K. Mishra and G. Bose, "Thickness dependent microstructure of $\mathrm{ZnO}$ films prepared by spin coating technique",Int. J. Nano and Biomaterials, Vol. 5, pp. 287, 2014.

[7] Abdulrahman, A.F., "The effect of different substrate-inclined angles on the characteristic properties of $\mathrm{ZnO}$ nanorods for $\mathrm{UV}$ photodetectors 
applications", J Mater Sci: Mater Electron, Vol. 31, pp.14357-14374, 2020.

[8] A. F. Abdulrahman, S. M Ahmed, N. M Ahmed and M. A Almessiere, "Fabrication, characterization of $\mathrm{ZnO}$ nanorods on the flexible substrate (Kapton tape) via chemical bath deposition for UV photodetector applications", AIP Conference Proceedings, Vol. 1875, No. 1, pp. $020004,2017$.

[9] Ü. Özgür, Y. I. Alivov, C. Liu, A. Teke, M. A. Reshchikov, S., Dogan, V. Avrutin, S-J. Cho and H. Morkoç, "A comprehensive review of $\mathrm{ZnO}$ materials and devices",J. Appl. Phys., Vol. 98, pp. 041301, 2005.

[10] W. Yang, Z. Liu, D-L. Peng, F. Zhang, H. Huang, Y. Xie and Z. Wu, "Room-temperature deposition of transparent conducting Al-doped $\mathrm{ZnO}$ films by RF magnetron sputtering method",Appl. Surf. Sci., Vol. 255, pp.5669, 2009.

[11] K. Tanaka, T. Minemoto, and H. Takakura, "Analysis of heterointerface recombination by $\mathrm{Zn} 1{ }^{-x} \mathrm{Mg}^{x} \mathrm{O}$ for window layer of $\mathrm{Cu}(\mathrm{In}, \mathrm{Ga}) \mathrm{Se} 2$ solar cells",Solar Energy, Vol. 83, pp. 477, 2009.

[12] J. Dutta, A. V. Singh, S. Singhal and M. D. Upadhayay, "Design and simulation of a zinc oxide thin film bulk acoustic resonator filter for 2.6 GHz band applications", IETE J. Res, Vol.62 (1), pp.3-8, 2016.

[13] E. B. Magnusson, B. H. Williams, R. Manenti, M-S. Nam, A. Nersisyan, M. J. Peterer, A. Ardavan, and P. J. Leek, "Surface Acoustic Wave Devices on Bulk ZnO at Low Temperature", Appl. Phys. Lett., Vol. 106, pp. 063509, 2015.

[14] A. F. Abdulrahman, S. M. Ahmed and M. A. Almessiere, "Effect of the Growth Time on the Optical Properties of ZnO Nanorods Grown By Low Temperature Method", Digest Journal of Nanomaterials and Biostructures, Vol. 12, No. 4, pp. 1001-1009, 2017.

[15] D. Aryanto, P. Marwoto, T. Sudiro, M. D. Birowosuto, Sugianto and Sulhadi, "Structure evolution of zinc oxide thin films deposited by unbalance DC magnetron sputtering", AIP Conf. Proc. (New York: AIP Publishing), Vol.1729, No. 1, pp. 020039, 2016.

[16] M. Ying, S. Wang, T. Duan, B. Liao, X. Zhang, Z. Mei, X. Du, F. M. Gerriu, A. M. Fox, and G. A. Gehring, "The structure, optical and magnetic properties of arsenic implanted $\mathrm{ZnO}$ films prepared by molecular beam epitaxy", Mater. Lett., Vol. 171, pp. 121-124, 2016.

[17] M. A. Boukadhaba, A. Fouzri, V. Sallet, S. S. Hassani, G. Amiri, A. Lusson, and M. Oumezzine, "Characterization of $\mathrm{ZnO}$ thin film grown on c-plane substrates by MO-CVD: Effect of substrate annealing temperature, vicinal-cut angle and miscut direction", Superlattices and Microstruct., Vol. 85, pp. 820, 2015.

[18] Abdulrahman, Ahmed Fattah "The Influence of Various Reactants in the Growth Solution on the Morphological and Structural Properties of $\mathrm{ZnO}$ Nanorods", Passer Journal: Vol. 2: Iss. 2, Article 3, 2020.

[19] R.Garcia-Gutierrez, R. Rangel-Segura, M. Barboza-Flores, O. E. Contreras-Lopez, and D. Berman-Mendoza,"Luminescence and Structure of $\mathrm{ZnO}$ Grown by Physical Vapor Deposition", Advances in Materials Science and Engineering, Vol. 2012, ID 872597, 5 pages, 2012.

[20] R. Y. Mohammed, B. M. Ilyas, "Comparative study of chemically deposited CdS thin films and of the non-synthesized CdSO under pressure and temperature within first principles", Materials Today Communications, Vol. 25, pp.101518, 2020

[21] R. Y. Mohammed, S. Abduol, A. M. Mousa, "Correlation between Optical and Structural Properties of Chemically deposited CdS Thin Films", International Letters of Chemistry, Physics and Astronomy, ISSN: 2299-3843, Vol. 30, pp 146-158, 2014.

[22] A. F. Abdulrahman, S. M. Ahmed, N. M. Ahmed and M. A. Almessiere, "different substrates effects on the topography and the structure of the $\mathrm{ZnO}$ nanorods grown by chemical bath deposition method" Digest Journal of Nanomaterials and Biostructures, Vol. 11, No. 3, pp. 1007-1016, 2016.

[23] A. F. Abdulrahman, S. M. Ahmed, N. M. Ahmed and M. A. Almessiere, "Novel Process Using Oxygen and Air Bubbling In Chemical Bath Deposition Method For Vertically Well Aligned Arrays Of $\mathrm{ZnO}$ Nanorods", Digest Journal of Nanomaterials and Biostructures, Vol. 11, No. 4, p. 1073-1082, October - December, 2016.

[24] K. A. Mohammed, S. M. A. and R. Y. Mohammed, "Investigation of Structure, Optical, and Electrical Properties of CuS Thin Films by CBD Technique," crystals, Vol. 10, No. 8, pp. 684, 2020.

[25] A. K. Qasim, L. A. Jamil, and A. F. Abdulrahman, "Synthesis of RutileTio2 Nanorod Arrays for Efficient Solar Water Splitting Via MicrowaveAssisted Hydrothermal Method", Digest Journal of Nanomaterials and Biostructures, Vol. 15, No. 1, , pp. 157 - 165, January - March, 2020.
[26] A. F. Abdulrahman, S. M. Ahmed, and N. M. Ahmed, "Investigation of Optical Properties of ZnO Nanorods Grown on Different Substrates", Science Journal of UOZ, Vol. 6, No. 4, pp. 160 -165, December, 2018.

[27] A. A. Barzinjy, S. M. Hamad, A. F. Abdulrahman, S. J. Biro, and A. A. Ghafor, "Biosynthesis, Characterization and Mechanism of Formation of ZnO Nanoparticles using Petroselinum Crispum Leaf Extract", Current Organic Synth., Vol.17, pp.558-566, 2020.

[28] J. Hasnidawani, "Synthesis of $\mathrm{ZnO}$ nanostructures using sol-gel method",Procedia Chem.,Vol.19, pp. 211-216, 2016.

[29] A. F. Abdulrahman, "Study the Optical Properties of The Various Deposition Solutions of ZnO Nanorods Grown on Glass Substrate Using Chemical Bath Deposition Technique" Journal of Ovonic Research, Vol. 16, No. 3, pp. 181-188, 2020.

[30] A. F. Abdulrahman, S. M. Ahmed, N. M. Ahmed, and M. A. Almessiere, "Enhancement of ZnO Nanorods Properties Using Modified Chemical Bath Deposition Method: Effect of Precursor Concentration", Crystals, Vol. 10, pp. 386, 2020. 